Modeling the effects of aluminum and ammonium perchlorate addition on the detonation of the high explosives $\mathrm{C}_{4} \mathrm{H}_{8} \mathrm{O}_{8} \mathrm{~N}_{8}(\mathrm{HMX})$ and $\mathrm{C}_{3} \mathrm{H}_{6} \mathrm{O}_{6} \mathrm{~N}_{6}$ (RDX)

Donghyeon Baek, Bohoon Kim, and Jack J. Yoh

Citation: Journal of Applied Physics 124, 215905 (2018); doi: 10.1063/1.5058155

View online: https://doi.org/10.1063/1.5058155

View Table of Contents: http://aip.scitation.org/toc/jap/124/21

Published by the American Institute of Physics

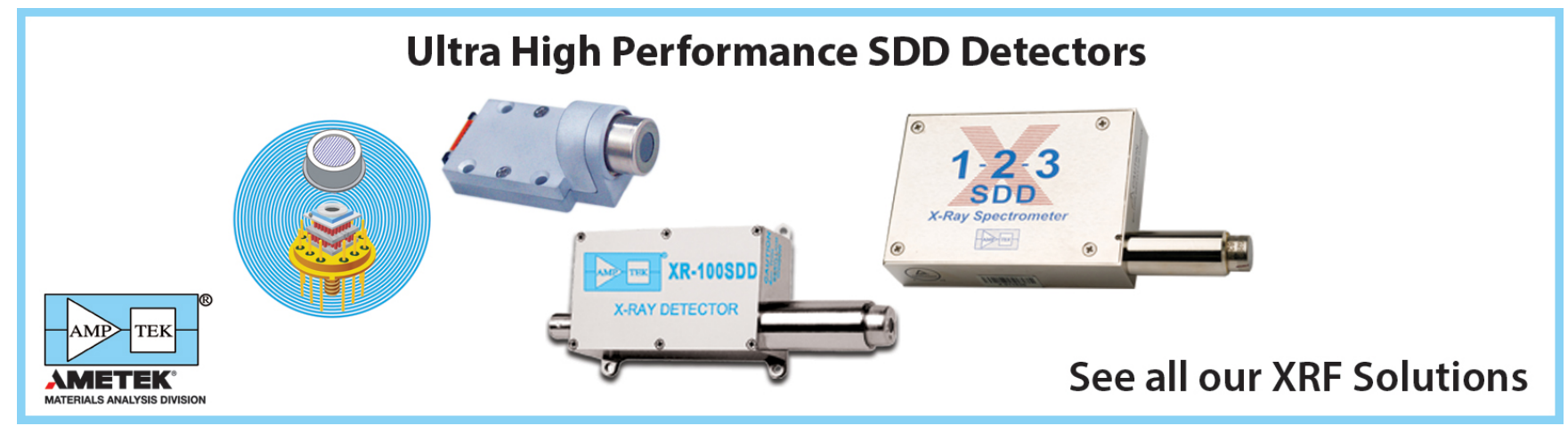




\title{
Modeling the effects of aluminum and ammonium perchlorate addition on the detonation of the high explosives $\mathrm{C}_{4} \mathrm{H}_{8} \mathrm{O}_{8} \mathrm{~N}_{8}(\mathrm{HMX})$ and $\mathrm{C}_{3} \mathrm{H}_{6} \mathrm{O}_{6} \mathrm{~N}_{6}$ (RDX)
}

\author{
Donghyeon Baek, ${ }^{1}$ Bohoon Kim, ${ }^{2}$ and Jack J. Yoh ${ }^{1, a)}$ \\ ${ }^{1}$ Department of Mechanical and Aerospace Engineering, Seoul National University, Seoul 151-742, \\ South Korea \\ ${ }^{2}$ Graduate Aeronautical Laboratory, California Institute of Technology, Pasadena, California 91125, USA
}

(Received 17 September 2018; accepted 15 November 2018; published online 4 December 2018)

\begin{abstract}
Metalized high explosives effectively tailor the explosion impulse at lowered detonation pressures of common high performance explosives such as $\mathrm{C}_{3} \mathrm{H}_{6} \mathrm{O}_{6} \mathrm{~N}_{6}$ (RDX) and $\mathrm{C}_{4} \mathrm{H}_{8} \mathrm{O}_{8} \mathrm{~N}_{8}$ (HMX). The presence of aluminum ( $\mathrm{Al})$ with and without ammonium perchlorate (AP) allows the subsequent burning for longer and sustained reactions of enhanced blast explosives. The modeling of reaction rate laws for three explosives with varied amounts of Al, AP, RDX, and HMX is reported. The model validation included the rate stick test for understanding the explosive reaction of the three samples and the large-scale gap test for determining their ignition sensitivity. The experimental results confirmed the accuracy of the model in simulating the shock sensitivity and the size effects before detonation failure. The effect of enhanced blast of these explosives in the presence of $\mathrm{Al}$ and AP is also reported. Published by AIP Publishing. https://doi.org/10.1063/1.5058155
\end{abstract}

\section{INTRODUCTION}

The addition of fine metallic powders to high performance explosives such as RDX and HMX can effectively extend the reaction duration, often tailored to meet certain performance needs. Al particles can react with hot explosive product gases from the detonation of either RDX or HMX, further burning in air, or with additional oxidizers such as ammonium perchlorate (AP) to increase the energy release during the whole reaction process. Furthermore, hot metal particles may be ejected from the fireballs of these metalized enhanced blast explosives. The fuel-rich condition due to the presence of Al may lower the peak pressure of detonation while enhancing the impulse for a longer subsequent burning. However, the effect of AP on providing additional oxygen for $\mathrm{Al}$ in hot product gases is still under investigation by many researchers.

Xiang et al. ${ }^{1}$ analyzed the detonation characteristics of HMX-Al explosives in underwater environments; by increasing the $\mathrm{Al}$ content, the peak detonation pressure decreased, while the impulse initially increased and then decreased, suggesting the existence of an optimal $\mathrm{Al}$ concentration for maximizing the impulse. Increasing the $\mathrm{Al}$ content also increased the bubble energy due to the subsequent $\mathrm{Al}$ reaction. In the subsequent study, ${ }^{2}$ the combustion characteristics of an $\mathrm{RDX}-\mathrm{Al}-\mathrm{AP}$ mixture were considered. The bubble energy due to the subsequent reaction was greater than that of RDX$\mathrm{Al}$ in the absence of AP, since AP promotes Al burning, and contributed to enhancing the underwater chemical explosion following the hydrodynamic bubble collapse. Kim et al. ${ }^{3}$ used a two-phase model to reproduce the detonation characteristics of HMX-Al explosives with increasing $\mathrm{Al}$ contents. As the $\mathrm{Al}$ content increased, the detonation velocity clearly declined, and the double peak due to the subsequent reaction

a)jjyoh@snu.ac.kr of $\mathrm{Al}$ was observed in the numerical simulations. A modified reaction model ${ }^{4,5}$ was used to determine the rate parameters of $50 \% \mathrm{RDX}$ and was verified by the unconfined rate stick and gap tests.

In this paper, a pressure-driven reaction model is developed and verified for understanding the chemical reaction characteristics of enhanced blast explosives summarized in Table I, which are designed to isolate the effect of $\mathrm{Al}$ and $\mathrm{AP}$ addition on the detonation of the basic explosives including $\mathrm{Al}, \mathrm{AP}$, and HTPB (hydroxyl terminated polybutadiene). In particular, we focus on the effects of a fuel-rich condition due to $\mathrm{Al}$ in excess and on how the oxygen-rich condition due to AP addition can boost the burning subsequent to the basic explosive detonation. A series of unconfined rate stick and large-scale gap tests (LSGTs) are conducted to assess the validity of the results obtained from the empirically inspired reaction rate law.

\section{EXPERIMENTAL TESTS}

\section{A. Unconfined rate stick test}

Detonation failure occurs when the chemical energy generated is smaller than the lateral loss due to the product expansion in the reaction zone. With increasing lateral loss, the detonation speed nears the sound speed, then the reaction stops or the detonation failure occurs. ${ }^{6}$

The unconfined rate stick test was performed to measure the fully developed detonation velocities with respect to the explosive radius before a detonation failure point. The test was conducted with the explosive length which was ten times the diameter to allow a fully developed detonation speed. ${ }^{4}$ If the explosive detonates successfully, the detector connected to each electric pin records the time that the detonation wave takes to reach the pins, and the detonation speed can be derived by a linear fit. In the case of failure, no signal is transmitted to the detector. 
TABLE I. Properties of the three explosives used.

\begin{tabular}{lc}
\hline \hline Explosives & \multicolumn{1}{c}{ Composition (\%) } \\
\hline RDX 25 & RDX 25, A1 35, AP 25, HTPB 15 \\
HMX 66 & HMX 66, Al 25, HTPB 9 \\
HMX 95 & HMX 95, HTPB 5 \\
\hline
\end{tabular}

Figure 1 shows the size effects for the three explosives of Table I. RDX 25 has the most gradual trend with the largest critical radius of detonation failure. This has the minimum concentration of the main explosive, RDX, while containing both Al and AP. The effect of lateral loss is greater when the explosive radius is of the same order of the reaction zone length. ${ }^{6}$ Hence, RDX 25 has the largest critical radius with a tendency to decline gradually from a larger radius. On the other hand, the reaction of HMX 95, which does not contain any metal, occurs within $1 \mu \mathrm{s}$. Therefore, when the radius is of the same order of the reaction zone length, the detonation velocity declines rapidly, as shown in Fig. 1.

\section{B. Large-scale gap test}

The large-scale gap test measures the sensitivity of the acceptor explosive. The detonation pressure wave generated by the impact at the donor is attenuated through the gap until reaching the acceptor charge. As shown in Fig. 2, a cylindrical configuration is used with pentolite (length of $50 \mathrm{~mm}$ and diameter of $50.8 \mathrm{~mm}$ ) as the donor and polymethyl methacrylate (PMMA) as the gap material. The PMMA thickness is increased incrementally using additional layers (disc) until the acceptor failure is witnessed with a probability of $50 \% .^{5}$ The critical gap thickness for each explosive and the corresponding shock pressure are shown in Table II. The gap thickness increased with increasing the percentage of basic explosive.

\section{REACTION RATE LAW}

The reactive flow model follows Eq. (1). The first term is associated with the effect of compression by the shock

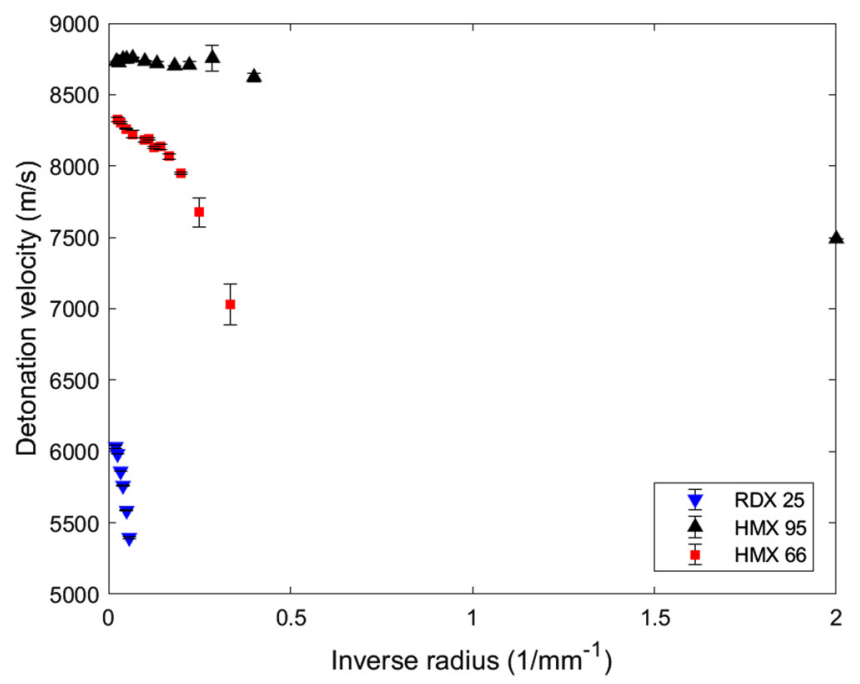

FIG. 1. Rate stick data for three explosives.

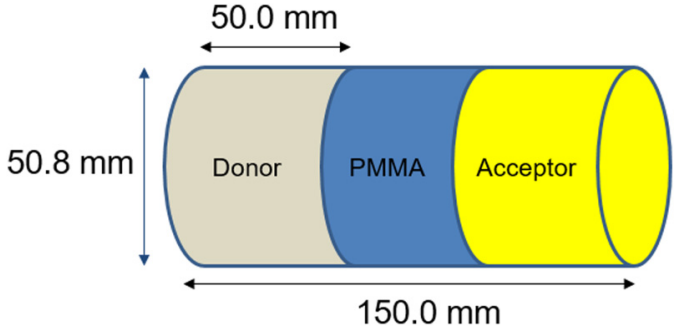

FIG. 2. LSGT configuration determining the maximum PMMA gap thickness for acceptor ignition upon donor initiation.

wave, which gives rise to a second (growth) term. $\lambda$ is the reaction progress, $p$ is the pressure, $t$ is the time, $\rho_{0}$ and $\rho$ are the initial and instantaneous densities, and $\mu=\rho / \rho_{0}-1$

$$
\frac{d \lambda}{d t}=\left.I(1-\lambda) \mu^{a}\right|_{0 \leq \lambda \leq 0.01}+\left.G(1-\lambda) p^{b}\right|_{0.01<\lambda \leq 1} .
$$

This model originates from the Lee-Tarver ignition and growth (I\&G) model $^{7}$ and, at the same time, complements the difficulty associated with determining the model parameters. The ignition parameter $(I)$ is determined by gap test simulations where Go/No Go is known for the corresponding gap thickness. The growth parameters $(G, b, a)$ are determined with the method described in Ref. 4. Their values are verified by reproducing the size effect curve from unconfined rate stick experiments. The reaction rate parameters used in our simulation are shown in Table III.

\section{GOVERNING EQUATION AND MODELING CONSTANTS}

We performed a multi-material numerical simulation for shock to detonation transition (SDT) by using a house code and applied a hybrid particle level-set method based on the ghost fluid method (GFM) framework to handle the interface between explosive and inert. ${ }^{8}$ The equation for mass, momentum, and energy conservation in a twodimensional axi-symmetry is

$$
\frac{\partial \vec{U}}{\partial t}+\frac{\partial \vec{E}}{\partial r}+\frac{\partial \vec{F}}{\partial z}=\vec{S}(\vec{U}),
$$

$$
\vec{U}=\left[\begin{array}{l}
\rho \\
\rho u_{r} \\
\rho u_{z} \\
\rho E
\end{array}\right], \quad \vec{E}=\left[\begin{array}{l}
\rho u_{r} \\
\rho u_{r}^{2}+p \\
\rho u_{r} u_{z} \\
u_{r}(\rho E+p)
\end{array}\right], \quad \vec{F}=\left[\begin{array}{l}
\rho u_{z} \\
\rho u_{z} u_{r} \\
\rho u_{z}^{2}+p \\
u_{z}(\rho E+p)
\end{array}\right],
$$

TABLE II. LSGT data for the three explosives.

\begin{tabular}{lccc}
\hline \hline Acceptor & $\begin{array}{c}\text { Density } \\
\left(\mathrm{kg} \mathrm{m}^{-3}\right)\end{array}$ & $\begin{array}{c}\text { Critical gap thickness } \\
(\mathrm{mm})\end{array}$ & $\begin{array}{c}\text { Shock pressure } \\
(\mathrm{GPa})\end{array}$ \\
\hline RDX 25 & 1830 & 21.45 & 6.248 \\
HMX 66 & 1900 & 43.79 & 2.859 \\
HMX 95 & 1820 & 53.49 & 1.827 \\
\hline
\end{tabular}




$$
\vec{S}=\left[\begin{array}{l}
-\frac{\rho u_{r}}{r} \varphi \\
\frac{s_{r r}-s_{\theta \theta}-\rho u_{r}^{2}}{r} \varphi+\eta\left(\frac{\partial s_{r r}}{\partial r}+\frac{\partial s_{z r}}{\partial z}\right) \\
\frac{s_{z r}-\rho u_{r} u_{z}}{r} \varphi+\eta\left(\frac{\partial s_{r z}}{\partial r}+\frac{\partial s_{z z}}{\partial z}\right) \\
\frac{u_{r} s_{r r}+u_{z} s_{r z}-u_{r}(\rho E+p)}{r} \varphi+\eta\left(\frac{\partial\left(u_{r} s_{r r}+u_{z} s_{r z}\right)}{\partial r}+\frac{\partial\left(u_{r} s_{z r}+u_{z} s_{z z}\right)}{\partial z}\right)
\end{array}\right],
$$

where $\varphi$ is 0 for rectangular and 1 for cylindrical coordinates, and $u_{z}$ and $u_{r}$ are the axial and radial velocities, respectively. $E=e+\left(u_{z}^{2}+u_{r}^{2}\right) / 2$ is the total energy per unit mass, $e$ is the specific internal energy, $p$ is the pressure, and $\eta$ is 0 for fluids and 1 for the gap material. For the LSGT, the deviatoric stresses of the PMMA discs are also needed such that

$$
\begin{gathered}
\dot{s}_{i j}=\dot{s}_{i j, t r}+\dot{s}_{i j, c o r}=\Omega_{i k} s_{k j}-s_{i k} \Omega_{k j}+2 G_{0}\left(\bar{D}_{i j}-D_{i j}^{p}\right), \\
\dot{s}_{i j, t r}=\Omega_{i k} s_{k j}-s_{i k} \Omega_{k j}+2 G_{0} \bar{D}_{i j}, \\
\dot{s}_{i j, c o r}=-H: D_{i j}^{p}=-2 G_{0} \Lambda N_{i j, t r},
\end{gathered}
$$

where $G_{0}$ is the shear modulus, and each operator is defined as follows:

$$
\begin{gathered}
\bar{D}_{i j}=D_{i j}-\frac{1}{3} D_{k k} \delta_{i j}, \quad D_{i j}=\frac{1}{2}\left(\frac{\partial u_{i}}{\partial x_{j}}+\frac{\partial u_{j}}{\partial x_{i}}\right), \\
\Omega_{i j}=\frac{1}{2}\left(\frac{\partial u_{i}}{\partial x_{j}}-\frac{\partial u_{j}}{\partial x_{i}}\right) .
\end{gathered}
$$

For time discretization, the third order Runge-Kutta method was used, with the convex essentially non-oscillatory (ENO) scheme for the spatial fluxes. ${ }^{8}$ The rate of burned mass

TABLE III. Modeling constants for each explosive.

\begin{tabular}{lccccc}
\hline \hline \multirow{4}{*}{ Reactant } & Parameter & RDX & HMX & HMX & \\
& $($ unit $)$ & 25 & 66 & 95 & Pentolite \\
& $\rho_{0}\left(\mathrm{~kg} \mathrm{~m}^{-3}\right)$ & 1830 & 1900 & 1820 & 1560 \\
& $C_{0}\left(\mathrm{~m} \mathrm{~s}^{-1}\right)$ & 2406 & 2467 & 2467 & $\ldots$ \\
& $S$ & 1.89 & 1.86 & 1.89 & $\ldots$ \\
& $\Gamma$ & 0.99 & 0.99 & 1.09 & $\ldots$ \\
Product & $A_{1}(\mathrm{GPa})$ & $\ldots$ & $\ldots$ & $\ldots$ & 12.82 \\
& $B_{1}(\mathrm{GPa})$ & $\ldots$ & $\ldots$ & $\ldots$ & 0 \\
& $C_{1}(\mathrm{GPa})$ & $\ldots$ & $\ldots$ & $\ldots$ & 119.3 \\
& $A_{2}(\mathrm{GPa})$ & 628.6 & 652.2 & 458.0 & 481.7 \\
& $B_{2}(\mathrm{GPa})$ & 4.80 & 4.10 & 8.30 & 8.93 \\
& $R_{1}$ & 5.10 & 4.23 & 3.721 & 4.70 \\
& $R_{2}$ & 1.30 & 0.75 & 1.068 & 1.05 \\
khemical & $\omega$ & 0.086 & 0.091 & 0.359 & 0.36 \\
& $I\left(\mu \mathrm{s}^{-1}\right)$ & 0.94 & 4.30 & 12.10 & 1.40 \\
& $a$ & 4.0 & 4.0 & 4.0 & 4.0 \\
& $G\left(\mu \mathrm{s}^{-1} \mathrm{GPa}{ }^{-b}\right)$ & 0.105 & 0.236 & 0.538 & 0.829 \\
& $b$ & 1.30 & 1.54 & 1.65 & 1.3 \\
\hline \hline
\end{tabular}

production is defined as

$$
\frac{\partial\left(\rho \lambda_{i}\right)}{\partial t}+\frac{\partial\left(\rho \lambda_{i} u_{j}\right)}{\partial x_{j}}=w_{i}
$$

where $w_{i}$ is the reaction rate and $\lambda_{i}$ is the reaction progress variable. The pressure in the unreacted state for donor and acceptor explosives was calculated, respectively, in the polynomial form ${ }^{9}$ and by the Mie-Gruneisen equation of state $(\mathrm{EOS})^{10}$

$$
\begin{gathered}
p_{\text {unreacted(donor) }}=A_{1}\left(\rho / \rho_{0}-1\right)^{1}+B_{1}\left(\rho / \rho_{0}-1\right)^{2} \\
+C_{1}\left(\rho / \rho_{0}-1\right)^{3}, \\
p_{\text {unreacted(acceptor) }}=p_{H}+\Gamma \rho\left(e-e_{H}\right),
\end{gathered}
$$

where $p_{H}$ and $e_{H}$ are the pressure and internal energy in the reference state according to the Hugoniot curve, respectively, $\Gamma$ is the Gruneisen gamma, and $p_{H}$ and $e_{H}$ are expressed as follows:

$$
\begin{gathered}
p_{H}=C_{0}^{2}\left(\frac{1}{\rho_{0}}-\frac{1}{\rho}\right) /\left[\frac{1}{\rho_{0}}-S\left(\frac{1}{\rho_{0}}-\frac{1}{\rho}\right)\right]^{2}, \\
e_{H}=C_{0}^{2}\left(\frac{1}{\rho_{0}}-\frac{1}{\rho}\right)^{2} / 2\left[\frac{1}{\rho_{0}}-S\left(\frac{1}{\rho_{0}}-\frac{1}{\rho}\right)\right]^{2}, \\
C_{0}=\left(\frac{\partial p}{\partial \rho}\right)^{1 / 2}, \\
S=d U_{\text {shock }} / d U_{\text {particle }}, \\
U_{\text {shock }}=C_{0}+S U_{\text {particle }},
\end{gathered}
$$

where $C_{0}$ is the speed of sound, $S$ is the linear Hugoniot slope, $U_{\text {shock }}$ is the shock wave speed, and $U_{\text {particle }}$ is the material particle velocity. An isentropic Jones-Wilkins-Lee (JWL) EOS was used to calculate the isentropic pressure $\left(p_{S}\right)$ of the reacted state of the explosive, with $v=\rho_{0} / \rho$

$$
p_{S}=A_{2} e^{-R_{1} v}+B_{2} e^{-R_{2} v}+C_{2} v^{-(\omega+1)} .
$$

The parameters in the above equation can be obtained with a metal cylinder expansion test or a thermochemical code running a cylinder test. ${ }^{11}$ The test measures the metal 
displacement due to the expansion of detonation product by impacting a copper-based explosive. Assuming that the expansion degree of the metal is equal to that of the detonation product, the parameters are obtained by fitting procedures. ${ }^{11}$ However, reflected waves are generated from the cylinder wall, causing product recompression by waves superposition. $^{12}$ Due to this high pressure effect, a nonisentropic JWL EOS rather than its isentropic form is required: the first law of thermodynamics for isentropic processes is given by

$$
\begin{gathered}
e_{S}=-p_{S} d v, \\
e_{S}=\frac{A_{2}}{R_{1}} e^{-R_{1} v}+\frac{B_{2}}{R_{2}} e^{-R_{2} v}+\frac{C_{2}}{\omega v^{\omega}},
\end{gathered}
$$

where $\omega$ is defined as follows:

$$
\omega=\left|\frac{v d p}{d e}\right|_{v} .
$$

Then, the Taylor series of the isentropic EOS is developed as follows:

$$
p=p_{S}+\left|\frac{d p}{d e}\right|_{v}\left(e-e_{S}\right)=p_{S}+\frac{\omega}{v}\left(e-e_{S}\right) .
$$

By combining the above equations, we obtain the following non-isentropic JWL EOS:

$$
p_{\text {reacted }}=A_{2}\left(1-\frac{\omega}{R_{1} v}\right) e^{-R_{1} v}+B_{2}\left(1-\frac{\omega}{R_{2} v}\right) e^{-R_{2} v}+\frac{\omega e}{v},
$$

where $A_{2}, B_{2}, C_{2}, R_{1}, R_{2}$, and $\omega$ are JWL EOS parameters. Since there were no experimental data for the target explosives, we calibrated the parameters reported by Fried et al. $^{13}$

The pressure parameters for the unreacted and reacted states are shown in Table III. The pressure was calculated as burned mass fraction as follows:

$$
p=(1-\lambda) p_{\text {unreacted }}+\lambda p_{\text {reacted }} .
$$

The pressure of the gap material, PMMA, was calculated with the following Mie-Gruneisen EOS: ${ }^{14}$

$$
\begin{aligned}
p_{P M M A}= & \Gamma_{0} E \\
& +\rho_{0} C_{0}^{2} \mu\left[1+\left(1-\frac{\Gamma_{0}}{2}\right) \mu\right] /\left[1-\left(S_{0}-1\right) \mu\right]^{2},
\end{aligned}
$$

where $\mu=\rho / \rho_{0}-1$. The Johnson-Cook model was used to calculate the yield stress $\left(\sigma_{Y}\right)$ due to the gap material deformation as follows:

$$
\sigma_{Y}=\left[A_{3}+B_{3}\left(\varepsilon^{p}\right)^{n}\right]\left(1+C_{3} \ln \dot{\varepsilon}^{p}\right)\left(1-\frac{T-T_{0}}{T_{m}-T_{0}}\right),
$$

\begin{tabular}{|c|c|}
\hline \multicolumn{2}{|l|}{ Mechanical parameter (unit) } \\
\hline$\rho_{0}\left(\mathrm{~kg} \mathrm{~m}^{-3}\right)$ & 1182 \\
\hline Young's modulus (GPa) & 0.42 \\
\hline Shear modulus (GPa) & 2.32 \\
\hline \multicolumn{2}{|l|}{ Thermal parameter (unit) } \\
\hline$C_{p}\left(\mathrm{~J} \mathrm{~kg}^{-1} \mathrm{~K}^{-1}\right)$ & 1466 \\
\hline$T_{0}(\mathrm{~K})$ & 300 \\
\hline$T_{m}(\mathrm{~K})$ & 330.3 \\
\hline \multicolumn{2}{|c|}{ Mie-Gruneisen equation of state (unit) } \\
\hline$C_{0}\left(\mathrm{~m} \mathrm{~s}^{-1}\right)$ & 2180 \\
\hline$S_{0}$ & 1.410 \\
\hline$\Gamma_{0}$ & 0.85 \\
\hline \multicolumn{2}{|l|}{ Jonson-Cook model (unit) } \\
\hline$A_{3}(\mathrm{GPa})$ & 0.76 \\
\hline$B_{3}(\mathrm{GPa})$ & 0.07 \\
\hline$C_{3}$ & 0.0 \\
\hline$m$ & 1.0 \\
\hline$n$ & 1.0 \\
\hline
\end{tabular}

where $\varepsilon^{P}$ is the effective plastic strain; $\dot{\varepsilon}^{P}$ is the effective plastic rate; $T_{m}$ is the melting point; $T_{0}$ is the room temperature; and $A_{3}, B_{3}, C_{3}$, and $n$ are modeling parameters for inert materials. Table IV shows the modeling constants for PMMA.
TABLE IV. Modeling constants for PMMA.

\section{SIMULATION RESULTS}

\section{A. Unconfined rate stick test}

For the unconfined rate stick simulation, there is a levelset boundary between void and explosive shown in Fig. 3: the length $\left(_{\mathrm{Lx}}\right.$ ) was $100 \mathrm{~mm}$ for RDX 25 and HMX 66 and $50 \mathrm{~mm}$ for HMX 95. Figure 4(a) shows the mesh resolution test results for RDX 25. The peak pressure of detonation at mesh resolution of $0.2 \mathrm{~mm}$ is confirmed to be the right choice for the simulation. Figure 4(b) compares the fully resolved detonation structures for the three explosives. The two HMX-based explosives have a high peak pressure and a sharp structure after detonation, and a short reaction zone length $(<0.5 \mathrm{~mm})$, while RDX 25 exhibits a low peak pressure and a longer reaction zone.

Table V shows that the calculated Chapman-Jouguet pressure, $p_{c j}$, was almost equal to that reported by Cheetah. Table $\mathrm{VI}^{15}$ shows values for illustrating the effect of $\mathrm{Al}$ and AP addition to the explosives.

This oxidizer and fuel addition allows the increase of total energy and the reduction of detonation energy so that the deflagration effect as opposed to detonation lasts longer. Adding Al and AP decreases the peak pressure by decreasing the detonation energy. However, Al and AP react after all of the basic explosive is consumed, increasing the total energy. Hence, RDX 25 has a longer tail than the other two explosives, as shown in Fig. 4(b). As regards HMX 66 with HMX 95,

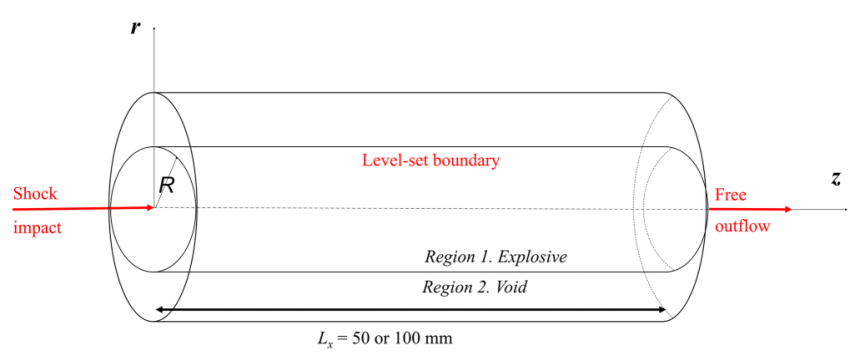

FIG. 3. Computational domain for the unconfined rate stick simulation. 


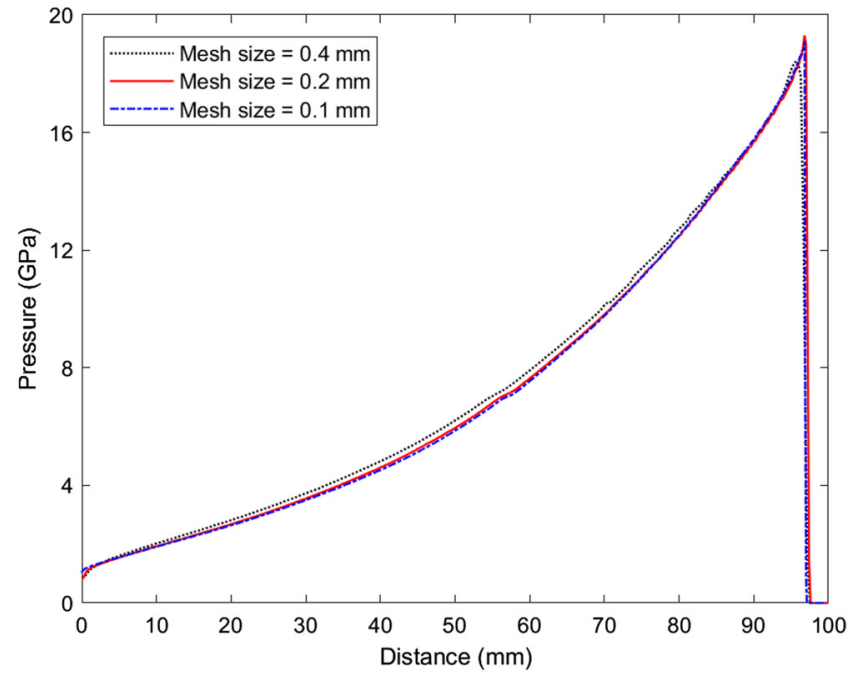

(a)

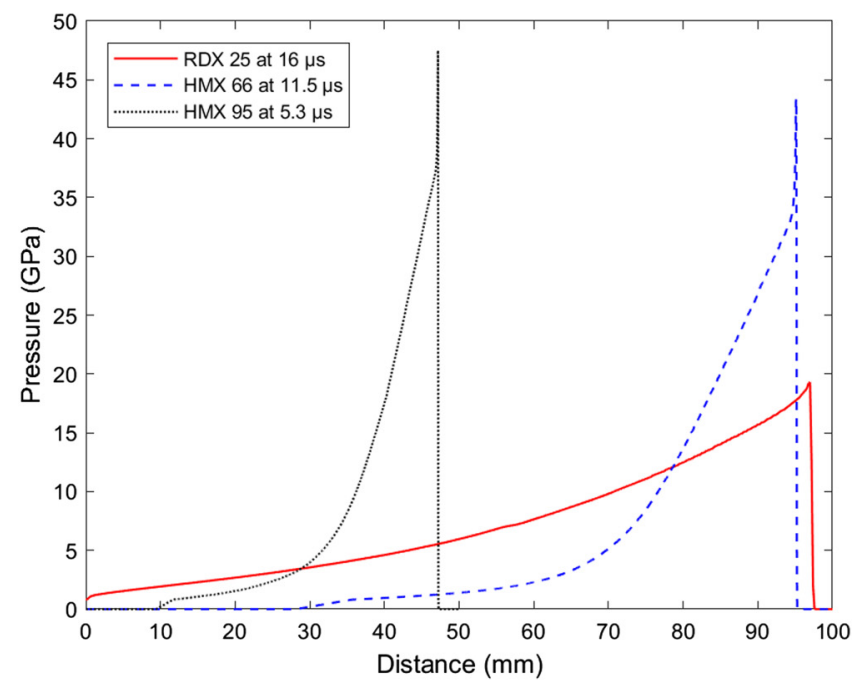

(b)

FIG. 4. Mesh resolution test results for RDX 25 with infinite radius (a) and comparison of the resolved detonation structures of all the explosives analyzed (b).

the tail of the Al-containing explosive is longer, indicating that the addition of $\mathrm{Al}$ and AP effectively increased the impulse and reduced the peak pressure. Figure 5 shows the pressure evolution during detonation propagation of RDX 25. Due to the subsequent burning of $\mathrm{Al}$ and $\mathrm{AP}$, the pressure range of RDX 25 is wider than that of the other two explosives. The combination of $\mathrm{Al}$ and $\mathrm{AP}$ increases the blast effect due to the above mentioned combustion characteristics.

TABLE V. Calculated detonation properties of three heterogeneous explosives.

\begin{tabular}{lccc}
\hline \hline Parameter (unit) & RDX 25 & HMX 66 & HMX 95 \\
\hline Peak pressure (GPa) & 19.3 & 43.0 & 47.5 \\
$p_{c j}(\mathrm{GPa})$ & 16.0 & 30.0 & 33.0 \\
$p_{c j}(\mathrm{GPa}$, Cheetah) & 16.6 & 29.1 & 34.1 \\
Reaction zone (mm) & 5.0 & 0.4 & 0.2 \\
Mesh size (mm) & 0.2 & 0.04 & 0.02 \\
\hline \hline
\end{tabular}

TABLE VI. Effects of Al and AP addition on RDX-based explosives. ${ }^{15}$

\begin{tabular}{lcc}
\hline \hline Explosive composition (\%) & $\begin{array}{c}\text { Total energy } \\
(\mathrm{kJ} / \mathrm{kg})\end{array}$ & $\begin{array}{c}\text { Detonation energy } \\
(\mathrm{kJ} / \mathrm{kg})\end{array}$ \\
\hline RDX 85, HTPB 15 & 5200 & 3708 \\
RDX 65, Al 20, HTPB 15 & 7917 & 3343 \\
RDX 20, AP 43, Al 25, HTPB 12 & 8505 & 1474 \\
\hline
\end{tabular}

The detonation velocity declines with decreasing stick radius because the energy loss due to product expansion increases as the radius becomes smaller. ${ }^{6}$ As a result, the peak pressure decreases and the pressure gradient decreases. Figure 6 shows the variations of detonation velocity depending on the size of the three explosives. The analytic solution corresponds to solving Eq. (26)

$$
\frac{R_{D}}{R}=-0.4 \frac{\left[1-\left(U_{S} / D\right)^{2}\right]^{-0.8}}{\ln \left[1-\left(U_{S} / D\right)^{2}\right]}\left(\frac{U_{S}}{D}\right)^{2 b-1}\left(1-\frac{U_{S}}{D}\right)
$$

Here, $R_{D}$ is the generalized radius, $b$ is the pressure sensitivity, $U_{S}$ is the detonation velocity, $D$ is the detonation velocity at infinite radius, and $R$ is the radius. One can plot the relation of the detonation velocity depending on the inverse radius obtained through the rate stick data. $D$ is calculated by extrapolating the data at inverse radius being zero. The optimum values of $R_{D}$ and $b$ which minimize the difference between Eq. (26) and experimental data are obtained by the curve fitting procedure.

\section{B. LSGT: Donor-gap pair}

The LSGT was designed to determine the Go/No Go of the acceptor charge. Before calculating the complete train of donor-gap-acceptor, the pressure attenuation in the gap was verified. Figure 7 compares the numerical results of the shock wave attenuation in the PMMA gap with the Naval Ordnance Laboratory (NOL) LSGT data. ${ }^{16}$

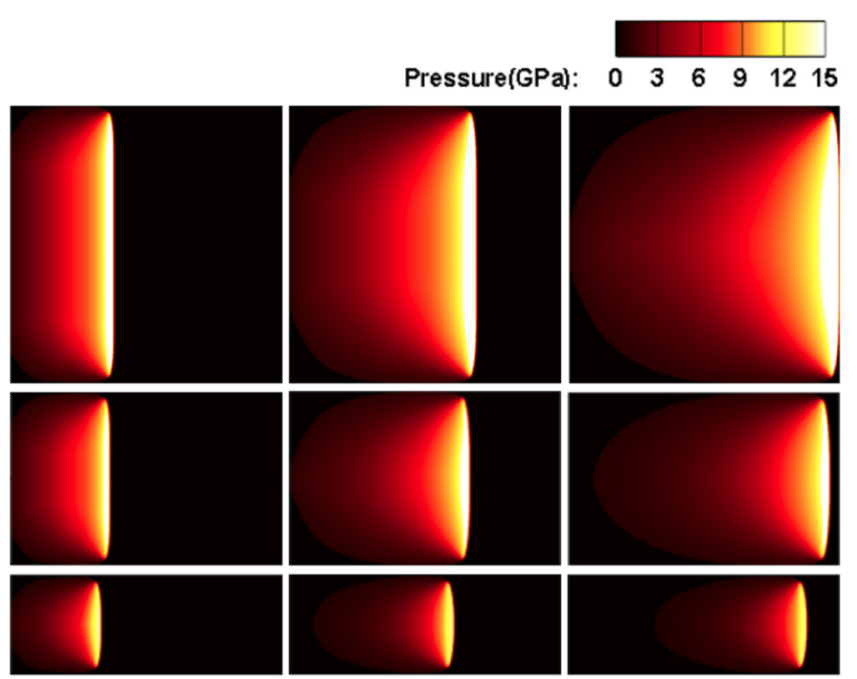

FIG. 5. RDX 25 rate stick pressure contour for radius 50, 30, and $17.5 \mathrm{~mm}$ cases (from top to bottom) at time $6.5,11.5$, and $16.5 \mu$ s (the length range was $0-100 \mathrm{~mm})$. 


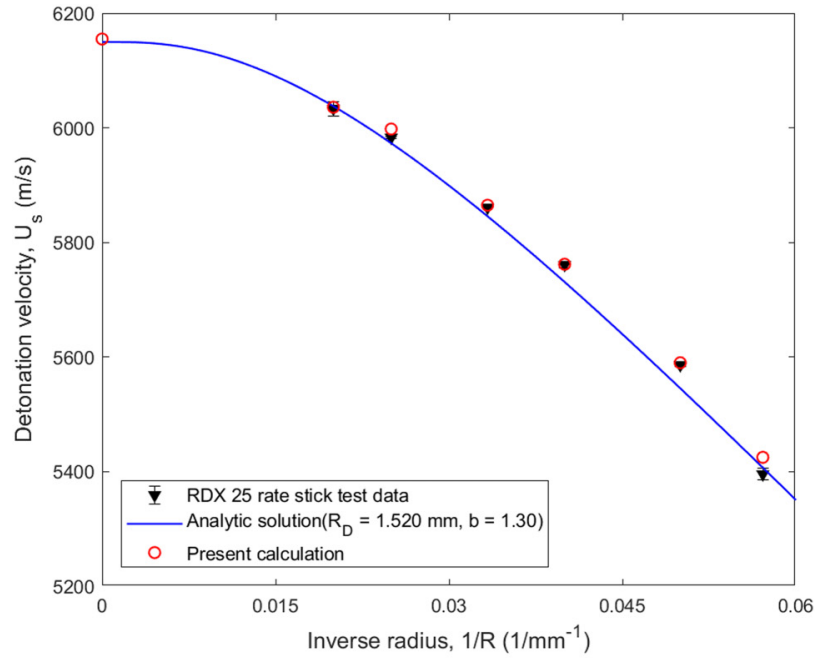

(a)

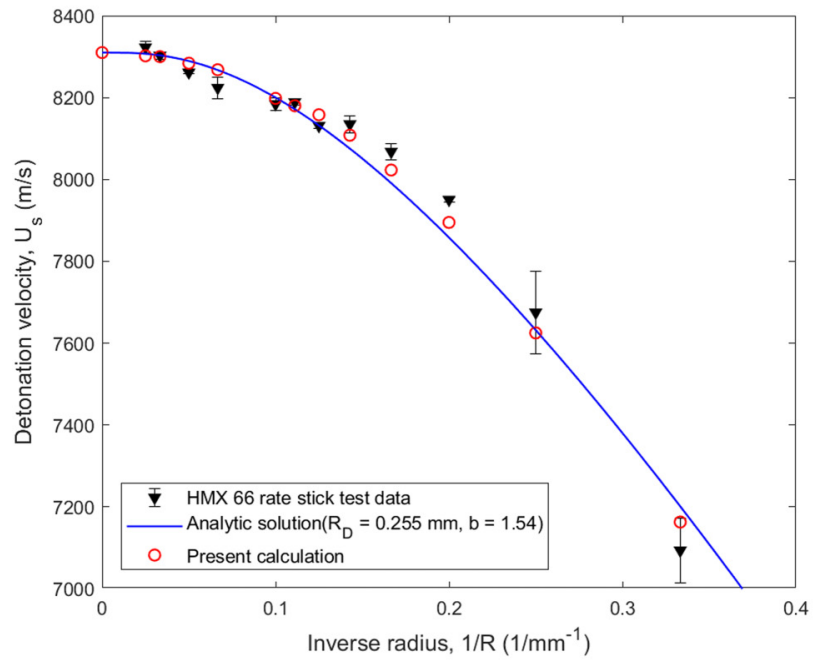

(b)

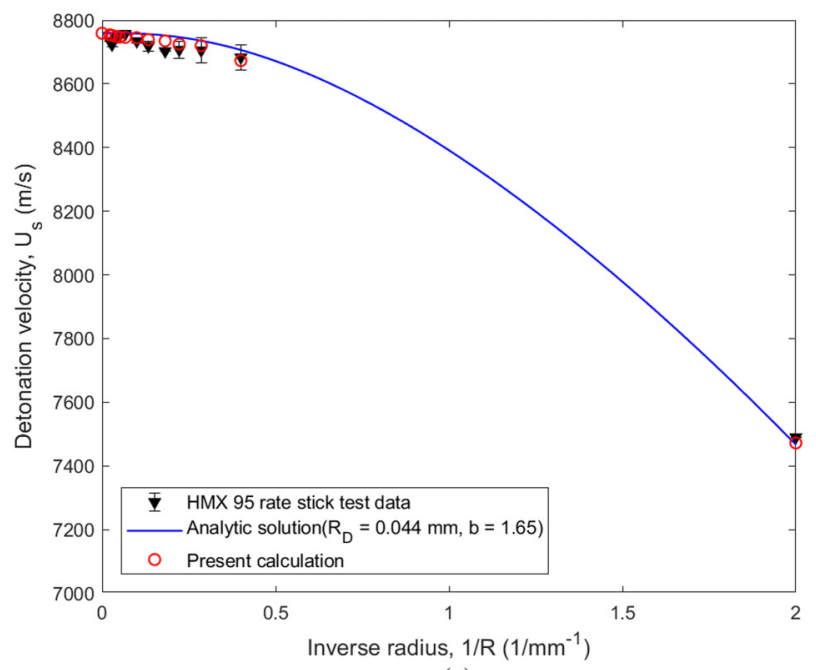

(c)

FIG. 6. Size effect curves for (a) RDX 25, (b) HMX 66, and (c) HMX 95.

With the configuration shown in Fig. 2, the pressure attenuation was calculated for a gap thickness of $60 \mathrm{~mm}$. The NOL and calculated data are in good agreement with those of shock pressure according to the measured thickness shown in the data. Because the impedance of the PMMA is smaller than that of the donor, the pressure wave transmitted is

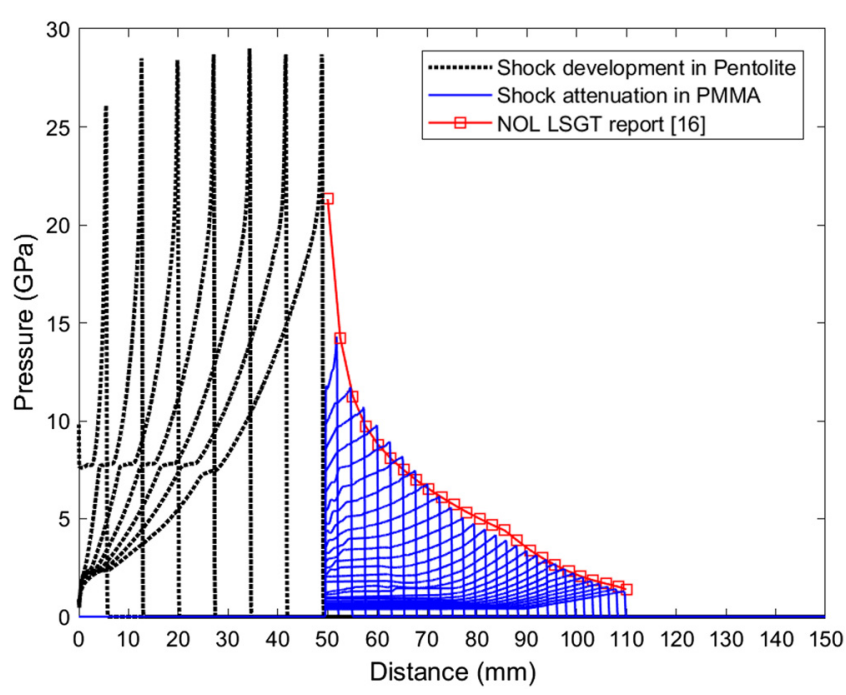

FIG. 7. Shock attenuation shown in PMMA.

decreased. As the shock wave crosses the interface of PMMA, the density of PMMA is increased due to a compression. The relevant pressure attenuation is calculated through Eq. (24).

\section{LSGT: Donor-gap-acceptor train}

The numerical simulation of the donor-gap-acceptor train was performed for all three explosives. The mesh size was $0.1 \mathrm{~mm}{ }^{4}$ The total length of the train is $150 \mathrm{~mm}$, the gap and acceptor length for all explosives are specified in Table VII. After the shock wave, attenuated in the PMMA gap, is transmitted to the acceptor, the reaction hardly occurs until the reaction progress of the acceptor reaches 0.01 . In the Go case, the reaction progress reaches 0.01 at the ignition stage, and the reaction continues to growth. In the No Go case, the reaction progress asymptotically reaches the 0.01 value. The reaction progress is maximum at the center of the interface between gap and acceptor until the reaction reaches the growth stage. When the reaction progress at this point becomes 0.01 , a detonation occurs, where the energy at this point exceeds the threshold value and the reaction takes place.

Figure 8 shows the propagation of the shock wave over time for HMX 95. Since the acceptor impedance is larger than the PMMA one, the transmitted shock wave is stronger in the acceptor in all cases. In the Go case, the incident shock wave turns into a fully developed detonation wave as the reaction progresses. This explosive turns into a fully developed detonation quicker than the other explosives

TABLE VII. Gap thickness and acceptor length for gap test simulations.

\begin{tabular}{lcccc}
\hline \hline & Go/No Go & RDX 25 & HMX 66 & HMX 95 \\
\hline PMMA gap (mm) & Go & 21.0 & 43.0 & 53.0 \\
& No Go & 22.0 & 44.0 & 54.0 \\
Acceptor (mm) & Go & 79.0 & 57.0 & 47.0 \\
& No Go & 78.0 & 56.0 & 46.0 \\
\hline
\end{tabular}




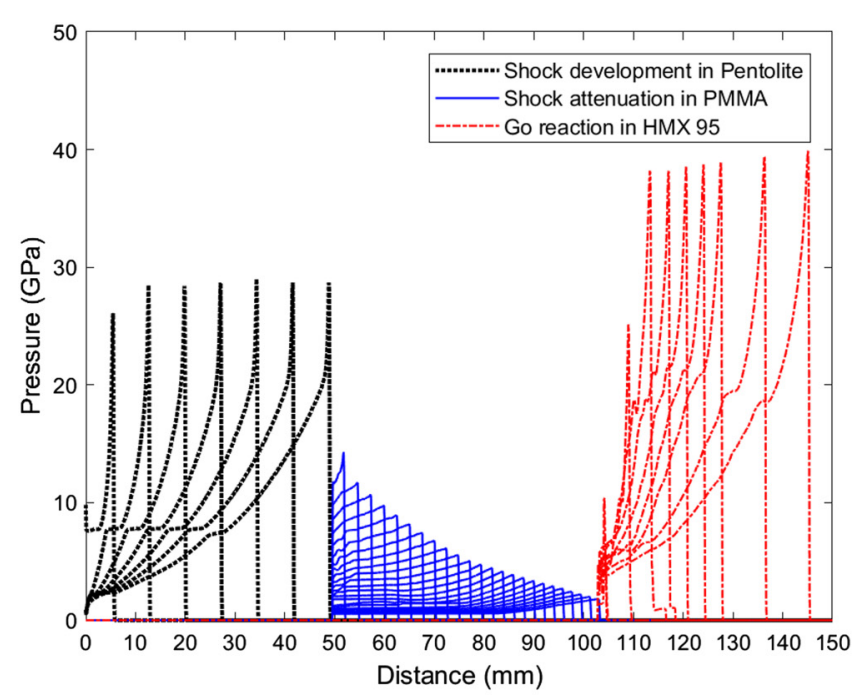

(a)

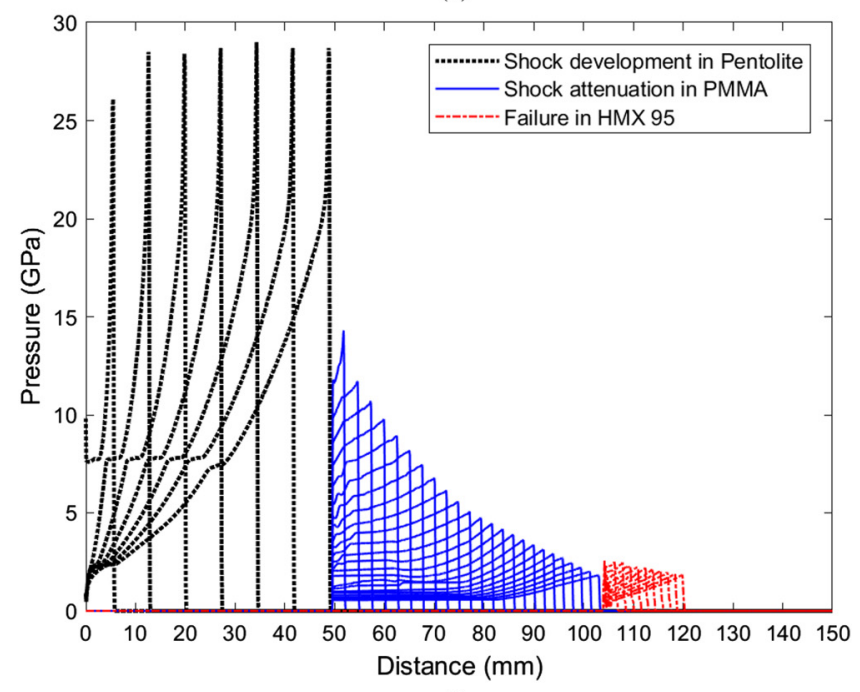

(b)

FIG. 8. Time trace of the pressure for the (a) Go (53-mm gap) and (b) No Go (54-mm gap) cases for HMX 95.

because of the short reaction length required. The critical gap thickness which was experimentally obtained in Table II is well predicted through the simulation results.

\section{CONCLUSIONS}

The pressure-driven reaction model is proposed for the enhanced blast explosives that contain metallic fuel. In particular, the characteristics of the reaction, subsequent to the addition of aluminum and ammonium perchlorate in the presence of HMX or RDX, were considered. The fuel-rich condition due to aluminum in excess together with the oxygen-rich condition due to ammonium perchlorate addition leads to an enhancement of the overall impulse of the explosion with extended duration of chemical reaction. Although shock initiation as measured by the gap test and size effect related to the rate stick tests were reproduced with a present reactive burn model, a more advanced study is desired to understand the longer-time behavior of these complicated materials.

\section{ACKNOWLEDGMENTS}

This study was carried out with the support of Agency for Defense Development and National Research Foundation of Korea (No. 2017R1A6A3A11031277) contracted through IAAT at Seoul National University. The authors are grateful to Dr. J. Park of ADD for providing the experimental data.

${ }^{1}$ D. L. Xiang, J. L. Rong, and J. Li, Propell. Explos. Pyrotech. 39, 65-73 (2014).

${ }^{2}$ D. L. Xiang, J. L. Rong, X. He, and Z. Feng, Cent. Eur. J. Energ. Mater. 14(1), 60-76 (2017).

${ }^{3}$ W. Kim, M. Gwak, and J. J. Yoh, Combust. Theor. Modell. 22, 378-393 (2018).

${ }^{4}$ B. Kim, J. Park, K. Lee, and J. J. Yoh, J. Appl. Phys. 116, 023512 (2014).

${ }^{5}$ B. Kim, J. Park, and J. J. Yoh, J. Appl. Phys. 119, 145902 (2016).

${ }^{6} \mathrm{H}$. Eyring, R. E. Powell, G. H. Duffey, and R. B. Parlin, The Stability of Detonation (Princeton University, 1948), pp. 132-143.

${ }^{7}$ E. L. Lee and C. M. Tarver, Phys. Fluids 23(12), 2362-2372 (1980).

${ }^{8}$ J. J. Yoh and K. Kim, J. Appl. Phys. 103, 113507 (2008).

${ }^{9}$ D. Piacesi, Naval Ordnance Laboratory, Report No. NOLTR-66-150, 1967, pp. 1-27.

${ }^{10}$ J. E. Guilkey, T. B. Harman, and B. Banerjee, Comput. Struct. 85, 660-674 (2007).

${ }^{11}$ P. M. Elek, V. V. Dzingalasevic, S. S. Jaramaz, and D. M. Mickovic, Therm. Sci. 19(1), 35-48 (2015).

${ }^{12}$ P. K. Tang, Lawrence Livermore National Laboratory, Report No. LA-UR-98-3365, 1998.

${ }^{13}$ L. E. Fried, W. M. Howard, and P. C. Souers, Lawrence Livermore National Laboratory, Report No. UCRL-MA-117541 Rev. 5, 1998.

${ }^{14}$ D. J. Steinberg, Lawrence Livermore National Laboratory, Report No. UCRL-MA-106439, 1996, pp. 1-7.

${ }^{15}$ I. F. Kobylkin, Combust. Explos. Shock Waves 45(6), 732-737 (2009).

${ }^{16}$ J. O. Erkman, D. J. Edwards, A. R. Clairmont, and D. Price, Naval Ordnance Laboratory, White Oak, Silver Spring, MD, 1973, p. 63. 